\title{
Perioperative treatments for resected upper tract urothelial carcinoma: a network meta-analysis
}

\author{
Xiao Yang ${ }^{1, *}$, Peng Li ${ }^{1, *}$, Xiaheng Deng ${ }^{1, *}$, Hongquan Dong ${ }^{2}$, Yidong Cheng ${ }^{1}$, Xiaolei \\ Zhang ${ }^{1}$, Chengdi Yang ${ }^{1}$, Jingyuan Tang ${ }^{1}$, Wenbo Yuan ${ }^{1}$, Xiaoting $\mathrm{Xu}^{1}$, Jun Tao $^{1}$, \\ Pengchao Li ${ }^{1}$, Haiwei Yang ${ }^{1}$, Qiang Lu${ }^{1}$, Min Gu${ }^{1}$ and Zengjun Wang ${ }^{1}$ \\ ${ }^{1}$ Department of Urology, The First Affiliated Hospital of Nanjing Medical University, Nanjing, China \\ 2 Department of Anesthesiology, The First Affiliated Hospital of Nanjing Medical University, Nanjing, China \\ * These authors have contributed equally to this work \\ Correspondence to: Qiang Lu, email: doctorlvqiang@sina.com \\ Min Gu, email: Lancetgu@aliyun.com \\ Keywords: upper tract urothelial carcinoma; perioperative treatment; network meta-analysis \\ Received: December 23,2015 Accepted: September 20,2016 Published: September 24, 2016
}

\section{ABSTRACT}

Background: Perioperative treatments have been used to improve prognosis in patients with upper tract urothelial carcinoma (UTUC). However, optimal management remains unestablished.

Methods: We searched the Embase, Web of Science and Cochrane databases for studies published before June 20, 2015. All included studies were categorised into three groups on the basis of the outcome reported (overall survival (OS), diseasespecific survival (DSS) and recurrence-free survival (RFS)). Relative hazard ratios (HRs) for death were calculated using random-effects Bayesian network meta-analysis methods. We also ranked the three different treatments in terms of three outcomes.

Results: A total of $\mathbf{3 1}$ trials with $\mathbf{8 1 0 0}$ patients were included. Compared with the control, adjuvant chemotherapy (AC) could improve OS, DSS and RFS by $32 \%$ (HR 0.68, 95\% CI 0.51-0.89), 29\% (HR 0.71, 95\% CI 0.54-0.89) and 51\% (HR $0.49,95 \%$ CI $0.23-0.85)$, respectively. We noted a marked prolongation of RFS in both intravesical chemotherapy (HR $0.32,95 \% \mathrm{CI} 0.09-0.69$ ) as well as concurrent radiotherapy and intravesical chemotherapy (HR $0.32,95 \% \mathrm{CI} 0.03-0.97$ ) than in the control. Neoadjuvant chemotherapy (NAC) showed a significant improvement in DSS relative to the control (HR $0.25,95 \% \mathrm{CI} 0.06-0.61$ ) and a distinct advantage over AC (HR 0.36, 95\% CI 0.08-0.90) or AR (HR 6.89, 95\% CI 1.25-18.66).

Conclusions: Our results showed that $\mathrm{AC}$; intravesical chemotherapy; and concurrent radiotherapy and intravesical chemotherapy could improve the prognosis of UTUC patients. NAC was found to be more favourable for UTUC than AC in terms of DSS.

\section{INTRODUCTION}

Upper tract urothelial carcinoma (UTUC) is an uncommon cause of tumours worldwide; it accounts for $5 \%$ of urothelial cancers and $7 \%-8 \%$ of all renal tumours [1]. The disease often results in worse prognosis than renal cell carcinoma. Radical nephroureterectomy (RNU) is the gold standard treatment for UTUC patients $[2,3]$. However, relapse in patients who underwent
RNU is highly common ( $28 \%-61.4 \%)$, with a five-year recurrence-free survival (RFS) rate of $69 \%[4,5]$. As a consequence, perioperative treatment has been logically employed to reduce relapse and prolong survival. Major perioperative treatments include adjuvant radiotherapy (AR), adjuvant chemotherapy (AC), neoadjuvant chemotherapy (NAC), concurrent chemoradiotherapy and intravesical chemotherapy. However, optimum perioperative therapy remains inconclusive. 
$\mathrm{AC}$ is the most widely used treatment in patients with cancer after undergoing surgery. Leow, J. J. et al. suggested the potential benefit in overall survival (OS) and disease-free survival (DFS) of cisplatin-based AC in UTUC [6]. In contrast to AC, NAC utilises agents to reduce the burden of tumour before patients undergo surgical treatment. A retrospective review found that NAC may prolong the survival of patients compared with the matched cohort who underwent initial surgery, but additional trials are necessary to confirm the treatment's utility [7]. The role of AR for transitional cell carcinoma (TCC) also remains controversial [8]. Maulard-Durdux et al. [9] found that the local control of disease and survival were similar in both treatment and control groups. However, some other trials showed that radiotherapy may improve overall patient survival $[10,11]$. A previous meta-analysis comparing adjuvant radiation therapy with concurrent chemoradiotherapy revealed that concurrent chemoradiotherapy could improve the outcomes of patients with resected locally advanced upper tract urothelial malignancies [12]. Intravesical chemotherapy is intended to reduce the recurrence rate in UTUC patients who underwent RNU. Several studies [13-15] concluded that intravesical chemotherapy may significantly reduce the bladder malignancy recurrence rate and prolong the time to first bladder recurrence, which suggest the utility of intravesical chemotherapy in UTUC patients.

In this study, we aimed to assess the prognosis of UTUC patients who received different treatment strategies after RUN. When direct comparisons are unavailable, investigators can use Bayesian network meta-analysis to assess the efficacy of different treatment strategies indirectly. To establish the optimal treatment for UTUC patients who underwent RNU accompanied with removal of an ipsilateral bladder cuff, we conducted a network meta-analysis to evaluate the efficacy of major perioperative treatments, including $\mathrm{AR}, \mathrm{AC}$, NAC, concurrent chemoradiotherapy and intravesical chemotherapy.

\section{MATERIALS AND METHODS}

\section{Search strategy and selection criteria}

We searched PubMed, the Cochrane Collaboration Central Register of Controlled Clinical Trials, Web of Science and Embase for eligible studies. In the process, we used the keywords "upper tract urothelial carcinoma [Title/Abstract] AND (chemotherapy [Title/Abstract] OR radiotherapy [Title/Abstract] OR intravesical chemotherapy [Title/Abstract])" and other related words to search for studies published until the end of June 20, 2015. We did not impose any restriction on the publication date or publication status. The search strategies are summarised in Figure 1. We also searched for additional relevant studies by browsing the bibliographies of the included trials and related reviews.

We included case-control studies that compared at least one of the five perioperative treatments described above with placebo or with another treatment involved. We chose the latest updated data for analysis if two or more studies report the same trials at different follow-up periods. We excluded the studies that contained none of the five treatment strategies. To ensure the accuracy and repeatability of our study, two researchers reviewed all of the eligible studies to determine which studies satisfied the inclusion criteria. Conflicts were resolved by a third reviewer.

\section{Data extraction and synthesis}

Baseline characteristics, selection criteria, treatment strategies and outcomes were extracted independently by two investigators. Any disagreement was resolved by a third investigator. We focused on the following outcomes: DSS, OS and RFS(Including local, intravesical and contralateral upper tract recurrence).

We divided all of the studies into three groups on the basis of the three outcomes described above. One study would be classified under different groups if two or more outcomes were reported by the work.

We considered the hazard ratio as our outcome measure because this parameter can provide intuitive comparison of different treatments and is often adjusted for confounders. When HRs were not reported in the studies, we obtain estimates of the value on the basis of the data provided in the manuscripts under study as we described previously [16].

\section{Statistical analysis}

The pooled HR with corresponding 95\% confidence interval (CI) was calculated in accordance with Tierney's method [17]. Bayesian network metaanalysis was performed with WinBUGS version 1.4.3 (MRC Biostatistics Unit, Cambridge, UK). We used an indirect comparison model to calculate the HRs in two incomparable heal methods. After setting randomised starting values, we used 100000 times simulated annealing, yielding 200000 iterations (100000 per chain) to obtain the HR of model parameters. The convergence of iterations was assessed with Gelman-Rubin-Brooks statistic [18].

\section{Quality evaluation}

Quality evaluation of each included study was performed utilising the Newcastle-Ottawa Scale (NOS) 
Table 1: Characteristics of the studies included in the meta-analysis

\begin{tabular}{|c|c|c|c|c|c|c|c|c|c|c|c|c|c|}
\hline \multirow[t]{2}{*}{ Author } & \multirow[t]{2}{*}{ Year } & \multirow[t]{2}{*}{ Country } & \multirow[t]{2}{*}{ Number } & \multirow[t]{2}{*}{ Stage } & \multirow[t]{2}{*}{ Intervention } & \multicolumn{2}{|c|}{$\begin{array}{l}\text { Disease specific } \\
\text { survival }\end{array}$} & \multicolumn{2}{|c|}{ Overall survival } & \multicolumn{2}{|c|}{$\begin{array}{l}\text { Recurrence free } \\
\text { survival }\end{array}$} & \multicolumn{2}{|c|}{$\begin{array}{l}\text { Follow-up } \\
\text { (months) }\end{array}$} \\
\hline & & & & & & HR & $95 \%$ CI & HR & $95 \% \mathrm{CI}$ & HR & $95 \%$ CI & Median & range \\
\hline Hall MC [32] & 1998 & American & 74 & $3-4$ & $\begin{array}{l}\text { AR vs. ctl } \\
\text { AR vs. ctl }\end{array}$ & $\begin{array}{l}0.98 \\
0.87\end{array}$ & $\begin{array}{l}{[0.42,2.25]} \\
{[0.32,2.36]}\end{array}$ & & & & & 21 & {$[1,236]$} \\
\hline Lee S. E. [37] & 2006 & Korea & 27 & 3 & AC vs. ctl & 0.62 & {$[0.18,2.17]$} & & & & & 48 & {$[25,102]$} \\
\hline Seitz C. [38] & 2010 & $\begin{array}{l}\text { Spain+Italy+Ameri } \\
\text { can+Japan+Canada } \\
+ \text { Germany }\end{array}$ & 754 & $1-4$ & AC vs. ctl & 0.40 & {$[0.24,0.63]$} & & & 0.42 & {$[0.27,0.67]$} & 40 & {$[18,75]$} \\
\hline $\begin{array}{l}\text { Kawashima } \\
\text { [39] }\end{array}$ & 2012 & Japan & 93 & 3 & $\mathrm{AC}$ vs. ctl & 0.21 & {$[0.06,0.66]$} & & & & & & \\
\hline Yafi F. A [20]. & 2014 & Canada & 305 & $1-4$ & AC vs. ctl & 0.78 & {$[0.40,1.50]$} & 0.70 & {$[0.29,1.66]$} & & & 17.8 & {$[5.5,46.8]$} \\
\hline Kluth L. A. [40] & 2013 & $\begin{array}{l}\text { Germany+France+J } \\
\text { apan+Austria+Italy } \\
+ \text { American }\end{array}$ & 242 & $1-4$ & $\begin{array}{l}\text { AC vs. ctl } \\
\text { AC vs. ctl }\end{array}$ & $\begin{array}{l}1.57 \\
0.87\end{array}$ & $\begin{array}{l}{[0.86,2.84]} \\
{[0.60,1.25]}\end{array}$ & & & & & 9 & \\
\hline Raman J. D. [41] & 2014 & France + American & 414 & $0-4$ & AC vs. ctl & 0.85 & {$[0.71,0.95]$} & & & & & 16 & {$[2,120]$} \\
\hline Kim T. S [42]. & 2013 & Korea & 65 & $1-4$ & AC vs. ctl & 0.52 & {$[0.17,1.82]$} & & & 0.07 & {$[0.01,0.31]$} & 34 & {$[12,114]$} \\
\hline Porten S. [7] & 2014 & American & 112 & $0-4$ & NAC vs. ctl & 0.19 & {$[0.06,0.61]$} & & & & & & \\
\hline Huang [22] & 2015 & ChinaTaiwan+USA & 171 & $1-4$ & AC vs. ctl & 0.60 & {$[0.34,1.05]$} & 0.51 & {$[0.34,0.74]$} & 0.61 & {$[0.45,0.83]$} & 35.8 & {$[3.4,125.2]$} \\
\hline Lee [21] & 2015 & Korea & 324 & $1-4$ & $\mathrm{AC}$ vs. ctl & 0.74 & {$[0.49,1.13]$} & 0.74 & {$[0.49,1.11]$} & & & 53.9 & {$[1,297]$} \\
\hline $\begin{array}{l}\text { Kuriyama } \quad M \\
{[43]}\end{array}$ & 1987 & Japan & 37 & $1-3$ & AC vs. ctl & & & 1.37 & {$[0.49,3.85]$} & 0.56 & {$[0.10,3.12]$} & & \\
\hline Cozad SC [44] & 1992 & American & 26 & 3 & AR vs. ctl & & & 0.55 & {$[0.24,1.25]$} & 0.19 & {$[0.01,2.63]$} & 13.5 & {$[3,311]$} \\
\hline Sengeløv L [23] & 1994 & Denmark & 240 & $1-4$ & AC vs. ctl & & & 0.41 & {$[0.30,0.57]$} & & & & \\
\hline Suzuki S [45] & 2004 & Japan & 56 & $1-4$ & AC vs. ctl & & & 0.60 & {$[0.25,1.45]$} & & & 39 & {$[4,163]$} \\
\hline Czito B [12] & 2004 & American & 31 & $1-4$ & AR vs. radio & & & 0.47 & {$[0.14,1.64]$} & & & 31.2 & {$[1.2,224.4]$} \\
\hline Kwak C [46] & 2006 & South Korea & 43 & $2-3$ & AC vs. ctl & & & 0.11 & {$[0.02,0.53]$} & & & 30.7 & {$[4.7,98.8]$} \\
\hline Soga N [47] & 2008 & Japan & 46 & $2-3$ & AC vs. ctl & & & 0.68 & {$[0.09,5.21]$} & 0.14 & {$[0.04,0.58]$} & & \\
\hline $\begin{array}{l}\text { Hellenthal N. J. } \\
\text { [48] }\end{array}$ & 2009 & $\begin{array}{l}\text { Austria+American+ } \\
\text { Italy+Germany+Ca } \\
\text { nada+France+Japan }\end{array}$ & 542 & $3-4$ & AC vs. ctl & & & 1.06 & {$[0.80,1.40]$} & & & 26 & {$[0,231]$} \\
\hline Chen B [11] & 2011 & China & 133 & $1-4$ & $\begin{array}{l}\text { radio+intravesical } \\
\text { vs. intravesical }\end{array}$ & & & 0.80 & {$[0.43,1.50]$} & 0.48 & {$[0.24,0.98]$} & 26.6 & \\
\hline Fan KH [49] & 2012 & China Taiwan & 40 & $0,3-4$ & AC vs. ctl & & & 1.01 & {$[0.28,3.57]$} & & & 61 & {$[22,93]$} \\
\hline Kitamura H [50] & 2012 & Japan & 29 & $1-4$ & NAC vs. ctl & & & 0.38 & {$[0.15,0.94]$} & & & 81 & {$[19,201]$} \\
\hline
\end{tabular}




\begin{tabular}{|c|c|c|c|c|c|c|c|c|c|c|c|}
\hline Jwa E [10] & 2014 & Korea & 127 & $1-4$ & $\begin{array}{l}\text { AC vs. ctl } \\
\text { AR vs. ctl }\end{array}$ & $\begin{array}{l}0.91 \\
0.98\end{array}$ & $\begin{array}{l}{[0.52,1.58]} \\
{[0.51,1.90]}\end{array}$ & & & 38.3 & {$[7.3,154.3]$} \\
\hline Cozad SC [51] & 1995 & American & 67 & $1-4$ & AR vs. ctl & & & 0.23 & {$[0.01,3.71]$} & & \\
\hline Sakamoto N [52] & 2001 & Japan & 25 & $1-2$ & $\begin{array}{l}\text { postoperative } \\
\text { instillation vs. ctl }\end{array}$ & & & 0.12 & {$[0.01,1.07]$} & 45 & {$[6,65]$} \\
\hline Wu W. J. [13] & 2010 & China Taiwan & 196 & $1-3$ & $\begin{array}{l}\text { postoperative } \\
\text { instillation vs. ctl } \\
\text { postoperative } \\
\text { instillation vs. ctl }\end{array}$ & & & $\begin{array}{l}1.88 \\
0.95\end{array}$ & $\begin{array}{l}{[0.89,3.95]} \\
{[0.47,1.93]}\end{array}$ & & {$[12,182]$} \\
\hline $\begin{array}{l}\text { Vassilakopoulou } \\
\text { M [26] }\end{array}$ & 2011 & Greece+France & 627 & $3-4$ & $\begin{array}{l}\text { AC vs. ctl } \\
\text { AC vs. ctl }\end{array}$ & & & $\begin{array}{l}1.43 \\
1.10\end{array}$ & $\begin{array}{l}{[0.52,3.85]} \\
{[0.83,1.47]}\end{array}$ & 22.5 & {$[10,50]$} \\
\hline O'Brien T [14] & 2011 & United Kingdom & 239 & $1-4$ & $\begin{array}{l}\text { postoperative } \\
\text { instillation vs. ctl }\end{array}$ & & & 0.66 & {$[0.35,1.28]$} & & \\
\hline Ito $A(160)$ [35] & 2013 & Japan & 72 & $1-3$ & $\begin{array}{l}\text { AC vs. ctl } \\
\text { postoperative } \\
\text { instillation vs. ctl }\end{array}$ & & & $\begin{array}{l}1.13 \\
0.26\end{array}$ & $\begin{array}{l}{[0.30,4.19]} \\
{[0.07,0.91]}\end{array}$ & & \\
\hline Ito $\mathrm{A}(70)[15]$ & 2013 & Japan & 72 & $1-3$ & $\begin{array}{l}\text { AC vs. ctl } \\
\text { postoperative } \\
\text { instillation vs. ctl } \\
\text { radio+intravesical } \\
\text { vs. intravesical }\end{array}$ & & & $\begin{array}{l}1.16 \\
0.02 \\
6.45\end{array}$ & $\begin{array}{l}{[0.18,7.37]} \\
{[0.01,0.53]} \\
{[0.50,83.2]}\end{array}$ & & \\
\hline Shirotake [53] & 2015 & Japan & 839 & $1-4$ & AC vs. ctl & & & 1.22 & {$[1.02,1.44]$} & 32 & {$[16,62]$} \\
\hline
\end{tabular}

Abbreviations: AR: adjuvant radiotherapy, AC: adjuvant chemotherapy, NAC: neoadjuvant chemotherapy

[19]. The assessment consisted of three major categories: selection (four items, one star for each), comparability (one item, up to two stars) and exposure (three items, one star for each). A maximum of nine stars can be given to one study. A final score of six stars or more was regarded as high quality.

\section{RESULTS}

The titles and abstracts of 1157 potentially relevant articles were reviewed for initial screening (Figure 1). We then retrieved the full text of potentially eligible articles for detailed information. A total of 31 articles (Table 1) satisfied the inclusion criteria and were included in the network meta-analysis, with 8100 patients receiving at least one of the five treatments. All of the included studies had been published and were available in full manuscripts.

\section{OS analysis}

Of the 31 included articles, 15 studies with a total of 2150 patients reported OS and were placed into the OS subgroup. Four treatments were adopted in the involved trials (Figure 2A). HRs were reported in all 11 trials. The results of our random-effects network meta-analysis for OS are summarised in Figure 3A. We find that, compared with control, AC improved patient OS by $32 \%$ (HR 0.68 , $95 \%$ CI $0.51-0.89)$. The trend of prolonged OS was also observed with NAC, but the effect was not significant (HR 0.46, 95\% CI 0.13-1.07). Meanwhile, the data showed no significant prolonging of OS with AR (HR 0.83, 95\% CI 0.39-1.47) and concurrent chemoradiotherapy (HR 0.54, 95\% CI 0.09-1.50). Furthermore, no significant improvement was observed between different treatment strategies (Figure 3A).

In Figure 4A, we summarised the possibility value (PV) of the different rankings of each treatment strategy. The control was most likely to be ranked with the shortest OS $(\mathrm{PV}=0.66)$. AR was ranked with the second shortest $\mathrm{OS}(\mathrm{PV}=0.33)$, followed by $\mathrm{AC}(\mathrm{PV}=0.42)$. The data showed that NAC $(\mathrm{PV}=0.45)$ and concurrent chemoradiotherapy ( $\mathrm{PV}=0.48)$ were both most likely to be ranked with the longest OS.

\section{DSS analysis}

A total of 2581 patients with three treatment strategies were included in the DSS group (Figure 2B). We summarised the results of the random-effects network meta-analysis for DSS in Figure 3B. Compared with the control, AC and NAC markedly prolonged DSS by $29 \%$ (HR 0.71, 95\% CI 0.54-0.89) and 75\% (HR 0.25, 95\% CI 0.06-0.61), respectively. By contrast, AR showed no significant improvement in DSS relative to the control (HR 1.02, 95\% CI 0.46-1.86). Notably, we observed a distinct improvement in DSS with NAC relative to AC 
(HR 0.36, 95\% CI 0.08-0.90). Moreover, AR showed poor DSS when compared with AC (HR 6.89, 95\% CI 1.2518.66). No statistically significant difference was observed between AR and AC (HR 1.46, 95\% CI 0.63-2.79).

The ranking of these three treatment strategies and control are displayed in Figure 4B. NAC $(\mathrm{PV}=0.95)$ or $\mathrm{AC}(\mathrm{PV}=0.71)$ were most likely ranked with longest or second-longest DSS. In addition, the control $(\mathrm{PV}=0.56)$ and $\mathrm{AR}(\mathrm{PV}=0.42)$ were both ranked as the poorest treatment strategies for DSS.

\section{RFS analysis}

A total of 15 studies with 3369 patients were included in the RFS subgroup (Figure 1). As the 15 studies didn't describe their definitions of recurrence definitely, we made a preminary analysis without separating local recurrence from intravesical recurrence and contralateral upper tract recurrence. The network of five treatment strategies and control is displayed in Figure 2C.

Compared with the control group, AC, intravesical chemotherapy and concurrent chemoradiotherapy were noted to improve the RFS (HR 0.49, 95\% CI 0.23-0.85 for $\mathrm{AC}, \mathrm{HR} 0.32$, 95\% CI $0.09-0.69$ for intravesical chemotherapy and HR 0.32 , 95\% CI 0.03-0.97 for concurrent radiotherapy and intravesical chemotherapy). Data showed no significant difference between the various treatment strategies.

In Figure 4C, we summarised the values of the different rankings of the five treatment strategies and control. The control was most likely to be ranked with the shortest RFS ( $\mathrm{PV}=0.65)$. In contrast to the control, both $\mathrm{AR}(\mathrm{PV}=0.42)$ and concurrent radiotherapy and intravesical chemotherapy $(\mathrm{PV}=0.40)$ were ranked with the highest RFS. Intravesical chemotherapy $(\mathrm{PV}=0.36)$, AC $(\mathrm{PV}=0.44)$ and concurrent chemoradiotherapy $(\mathrm{PV}=0.24)$ were most likely to be ranked as third, fourth and fifth, respectively.

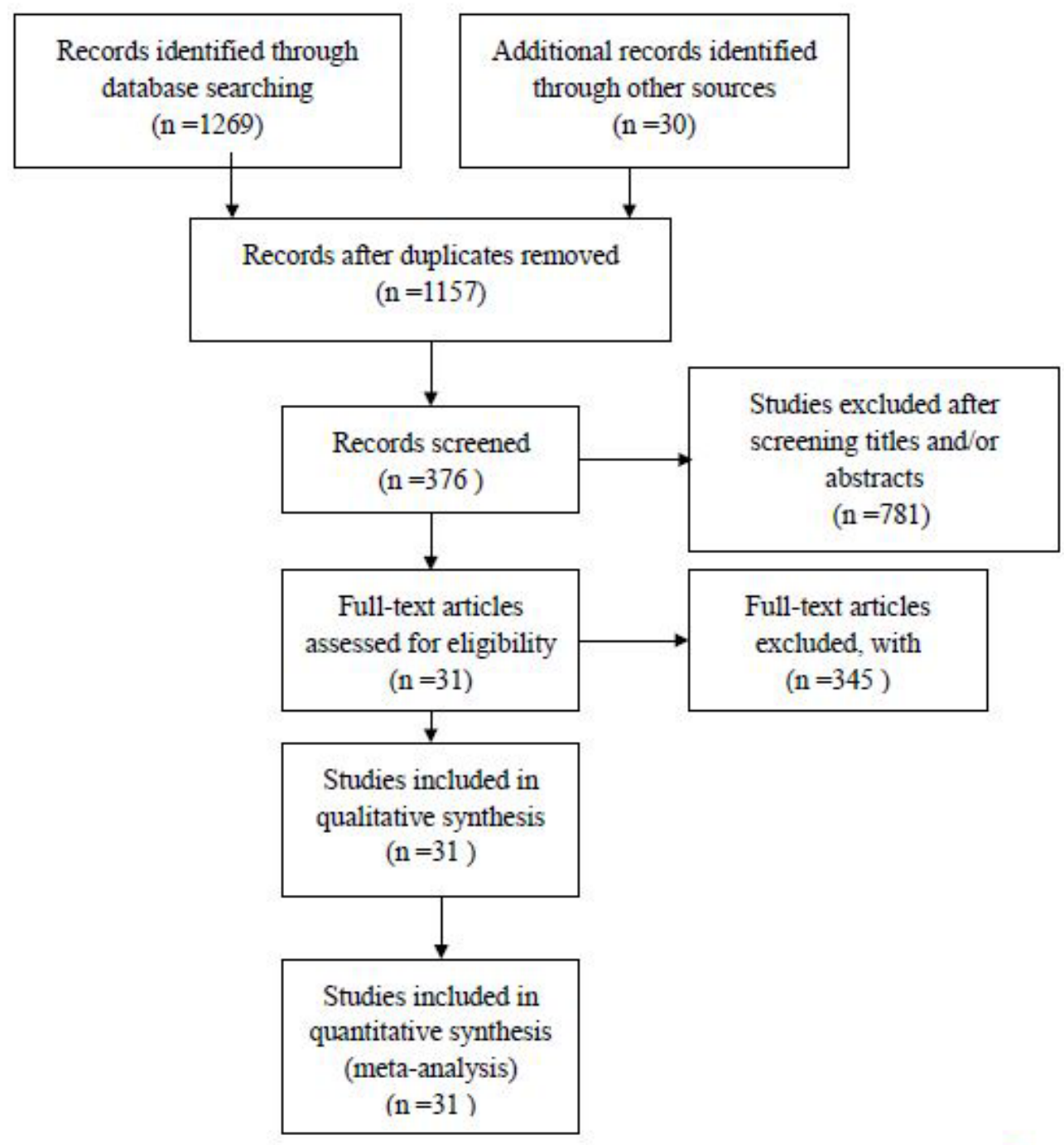

Figure 1: Literature search and selection 


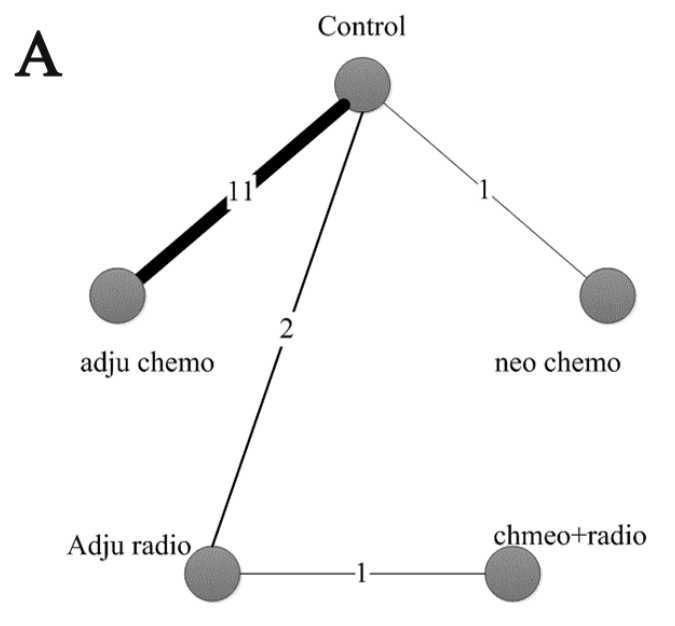

B
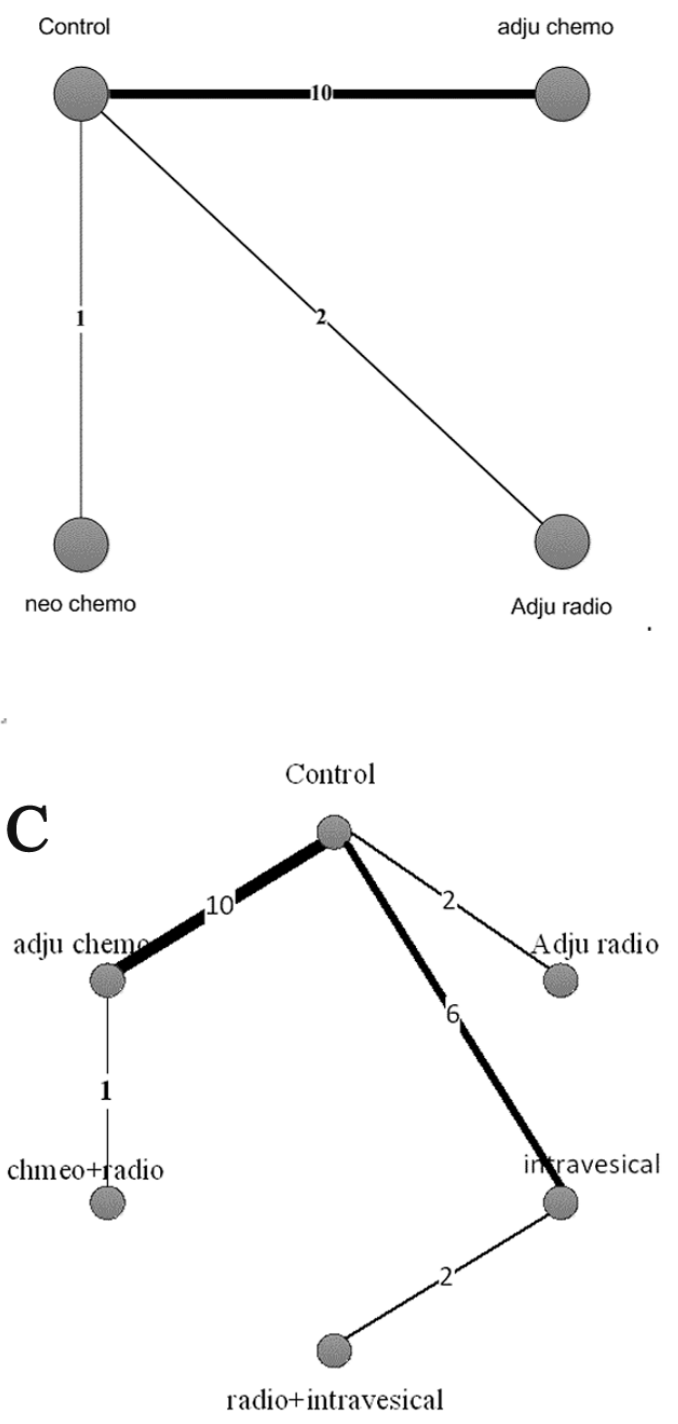

Figure 2: Network of comparisons of OS, DSS and RFS for Bayesian network meta-analysis. The width of each line is proportional to the number of trials (on the line) compared with the connected treatments. A OS, B DSS and C RFS. 
Table 2: Results of quality assessment by NOS

\begin{tabular}{|c|c|c|c|c|c|c|c|c|c|c|}
\hline Study & 1 & 2 & 3 & 4 & $\mathbf{5 A}$ & $5 B$ & 6 & 7 & 8 & Scores \\
\hline Hall MC 1998 & $*$ & $*$ & - & - & $*$ & - & * & $*$ & - & 5 \\
\hline Lee S. E. 2006 & $*$ & $*$ & - & $*$ & $*$ & $*$ & * & $*$ & - & 7 \\
\hline Seitz C. $\quad 2010$ & $*$ & $*$ & - & $*$ & $*$ & $*$ & $*$ & $*$ & - & 7 \\
\hline Kawashima A 2012 & $*$ & $*$ & - & $*$ & $*$ & * & $*$ & $*$ & - & 7 \\
\hline Yafi F. A 2014 & $*$ & $*$ & - & $*$ & $*$ & $*$ & * & $*$ & - & 7 \\
\hline Kluth L. A. 2013 & $*$ & $*$ & - & $*$ & $*$ & $*$ & * & $*$ & - & 7 \\
\hline Raman J. D. 2014 & $*$ & $*$ & - & $*$ & $*$ & $*$ & $*$ & $*$ & - & 7 \\
\hline Kim T. S 2013 & $*$ & $*$ & - & $*$ & $*$ & $*$ & * & $*$ & - & 7 \\
\hline Porten S. 2014 & $*$ & $*$ & - & $*$ & - & * & * & $*$ & - & 6 \\
\hline Huang $\quad 2015$ & $*$ & $*$ & - & $*$ & $*$ & $*$ & $*$ & $*$ & - & 7 \\
\hline Lee $\quad 2015$ & $*$ & $*$ & - & $*$ & $*$ & $*$ & * & $*$ & - & 7 \\
\hline Kuriyama M 1987 & $*$ & $*$ & - & $*$ & - & - & * & $*$ & - & 5 \\
\hline Cozad SC 1992 & $*$ & $*$ & - & $*$ & $*$ & - & * & $*$ & - & 6 \\
\hline Sengeløv L 1994 & $*$ & $*$ & - & $*$ & $*$ & $*$ & * & $*$ & - & 7 \\
\hline Suzuki 2004 & $*$ & $*$ & - & $*$ & - & $*$ & * & $*$ & - & 6 \\
\hline Czito B 2004 & $*$ & $*$ & - & $*$ & $*$ & - & * & $*$ & - & 6 \\
\hline Kwak C 2006 & $*$ & $*$ & - & $*$ & $*$ & $*$ & * & $*$ & - & 7 \\
\hline Soga N 2008 & $*$ & $*$ & - & $*$ & - & - & $*$ & $*$ & - & 5 \\
\hline Hellenthal N. J. 2009 & $*$ & $*$ & - & - & $*$ & $*$ & * & $*$ & - & 6 \\
\hline Chen B 2011 & $*$ & $*$ & - & $*$ & $*$ & * & * & $*$ & - & 7 \\
\hline Fan KH 2012 & $*$ & $*$ & - & $*$ & $*$ & * & * & $*$ & - & 7 \\
\hline Kitamura H 2012 & $*$ & $*$ & - & - & $*$ & $*$ & $*$ & $*$ & - & 6 \\
\hline Jwa E 2014 & $*$ & $*$ & - & $*$ & $*$ & $*$ & $*$ & $*$ & - & 7 \\
\hline Cozad SC 1995 & $*$ & * & - & $*$ & - & * & * & $*$ & - & 6 \\
\hline Sakamoto N 2001 & $*$ & $*$ & - & $*$ & $*$ & $*$ & * & $*$ & - & 7 \\
\hline Wu W. J 2010 & $*$ & $*$ & - & $*$ & $*$ & $*$ & $*$ & $*$ & - & 7 \\
\hline Vassilakopoulou M 2011 & $*$ & $*$ & - & $*$ & $*$ & $*$ & $*$ & $*$ & - & 7 \\
\hline O'Brien T 2011 & $*$ & * & - & $*$ & $*$ & - & * & $*$ & - & 6 \\
\hline Ito $\mathrm{A}(160) \quad 2013$ & $*$ & $*$ & - & $*$ & $*$ & * & $*$ & $*$ & - & 7 \\
\hline Ito A(70) 2013 & $*$ & $*$ & - & $*$ & $*$ & $*$ & * & $*$ & - & 7 \\
\hline Shirotake $\quad 2015$ & $*$ & $*$ & - & $*$ & $*$ & $*$ & $*$ & $*$ & - & 7 \\
\hline
\end{tabular}

1 indicates adequate definition of cases; 2 cases are representative of the population; 3 community controls; 4 controls have no history of UTUC; 5 study controls for tumour stage and grade; 5B study controls for additional factor(s); 6 ascertainment of exposure by blinded interview or record; 7 same method of ascertainment used for cases and controls; 8 similar non-response rates for cases and controls. 


\section{Quality assessment}

The results of quality assessment for the included studies using NOS are shown in Table 2. The scores range from five to seven stars; 28 studies scored six stars or more, indicating moderate or high quality.

\section{DISCUSSION}

To date, RNU remains as the gold standard treatment for high-risk UTUC. However, relapse and metastasis are highly common in UTUC patients after RNU, affecting long-term survival. Perioperative treatments have been used to reduce relapse and prolong survival. However, the optimal perioperative therapy is still uncertain.

Our network meta-analysis is the first study assessing different peri-surgical treatment strategies for UTUC. Our results suggest that both AC and NAC are advantageous over the control in terms of OS and DSS. Furthermore, AC prolongs the RFS by $51 \%$, whereas NAC exhibits no significant improvement of RFS. The prolongation of RFS is also observed in the patients who received intravesical chemotherapy or concurrent radiotherapy and intravesical chemotherapy. In terms of DSS, NAC shows better prognosis than AC and AR.

Controversial results on the effect of $\mathrm{AC}$ have been reported in the management of patients receiving RNU [20-23]. A definite consensus on this issue will unlikely be achieved until further evidence from an ongoing prospective trial is available ${ }^{[24]}$. Even so, our pooled results suggest that $\mathrm{AC}$ can improve $\mathrm{OS}$ by $32 \%$ relative to the control (HR $0.68,95 \%$ CI $0.51-0.89$ ). In terms of DSS, the improvement is also remarkable (HR 0.71, 95\% CI 0.54-0.89). For RFS, prolongation can be seen in $51 \%$ of the patients (HR $0.49,95 \%$ CI $0.23-0.85$ ). AC application after surgery shows many advantages. Through this strategy, we can assess the pathologic staging immediately, which means the absence of delay in treatment for high-risk patients and the reservation of local surgical treatment for non-responders [25]. Moreover, utilisation of $\mathrm{AC}$ can destroy the tumour cells that are locally implanted, retained or present in the blood cycle to form micrometastasis before or during surgical operation. These reasons may explain why AC prolongs patient survival by $51 \%$ than the control in our study.

Previous studies also reported conflicting outcomes in patients who received NAC [26-28]. In our study, NAC

A

OS

$0.68(0.51-$
$0.89)$

Adju chemo

Adn cheno

B

DSS

$\begin{array}{lcc}\text { Control } & 0.71(0.54- & 0.25(0.06- \\ & 0.89) & 0.61) \\ & \text { Adju chemo } & 0.36(0.08- \\ & & 0.90) \\ & & \text { Neo chemo } \\ & & \\ \text { C } & & \\ \text { RFS } & & \\ \text { Control } & 0.49(0.23-0.85) & 0.39(0.02-1.33) \\ & \text { Adju chemo } & 0.96(0.05-3.33) \\ & & \text { Adju radio }\end{array}$

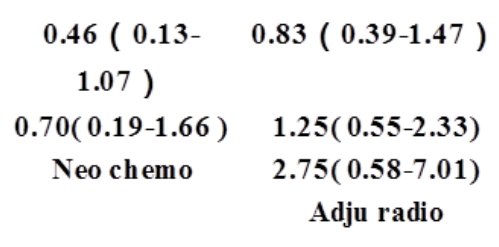

$0.70(0.19-1$

Neo chemo $2.75(0.58-7.01)$

$1.02(0.46-1.86)$

$1.46(0.63-2.79)$

$6.89(1.25-$

$18.66)$

Adju radio

\author{
$0.54(0.09-1.50)$ \\ 0.81(0.13-2.30) \\ 1.83(0.16-5.70) \\ 0.65(0.14-1.69) \\ Chmeo\&radio
}

0.32(0.03-0.97)

$0.78(0.06-2.36)$

4.33(0.06-13.83)

1.41(0.03-3.72)

1.02(0.15-2.90)

Radio\&

intravesical

Figure 3: Pooled HRs for OS (A), DSS (B) and RFS (C). The column treatment is compared with the row treatment. HRs with Bayesian $\mathrm{p}$ values less than 0.05 are indicated in green and those rescued are in red. 
OS

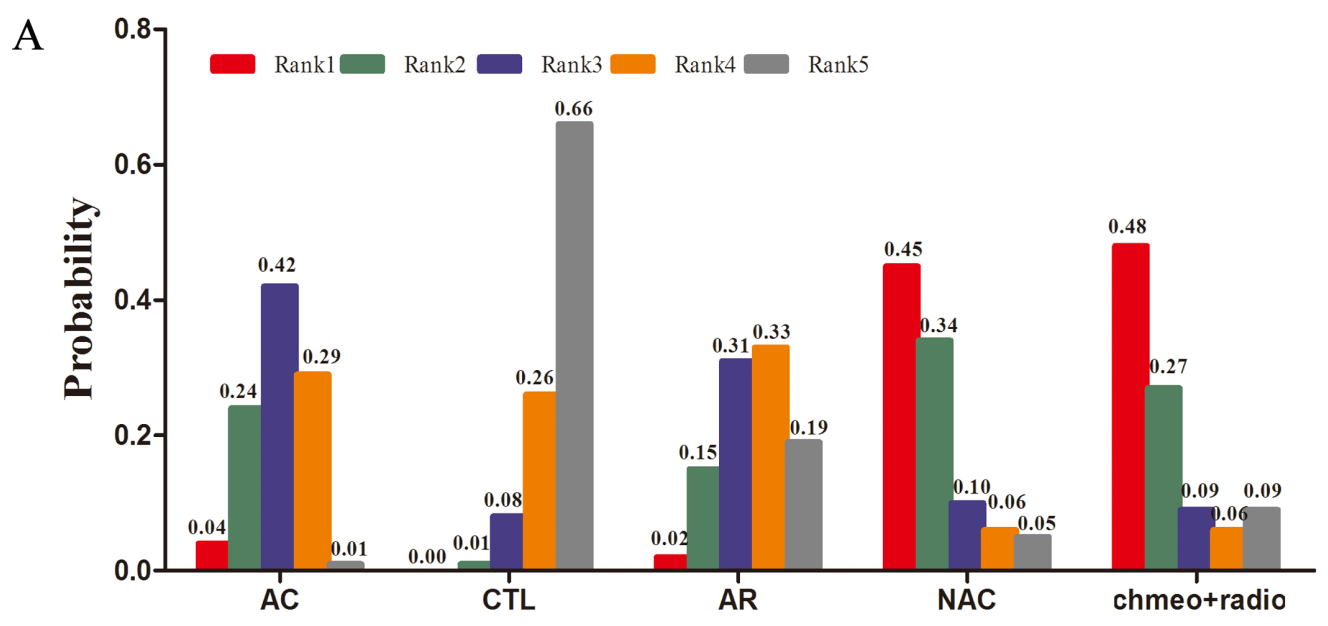

DSS

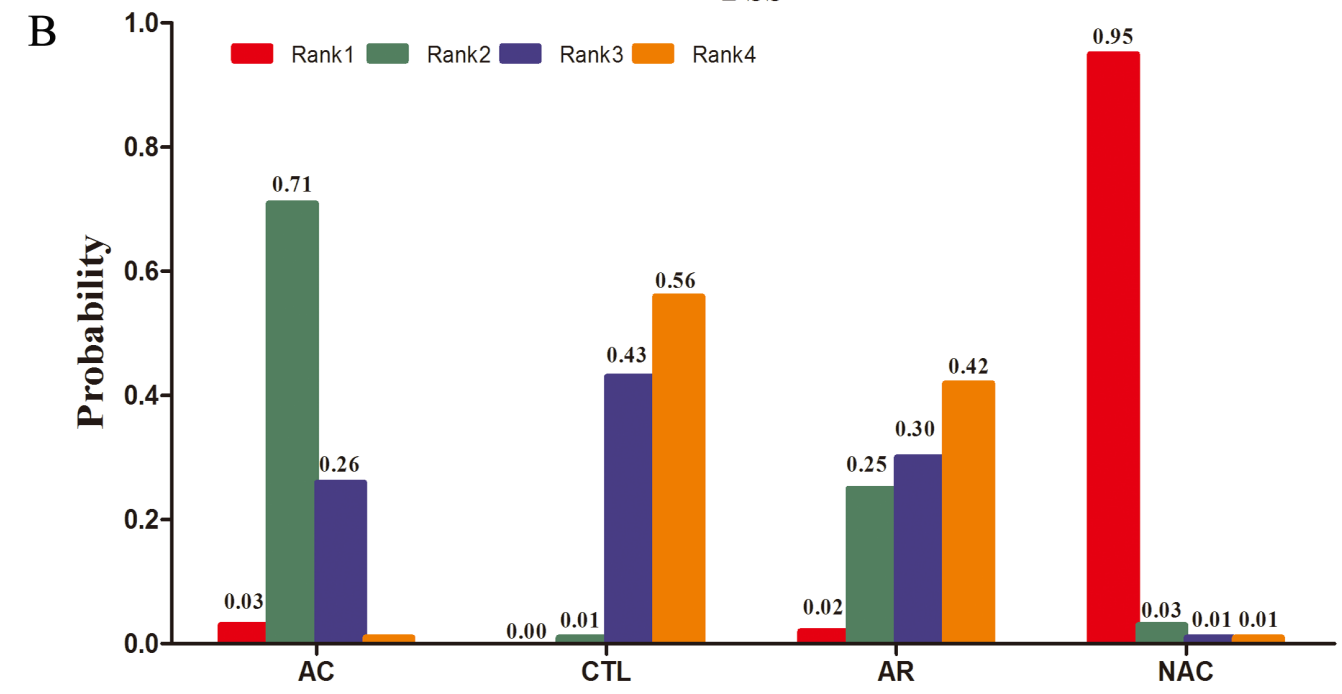

RFS

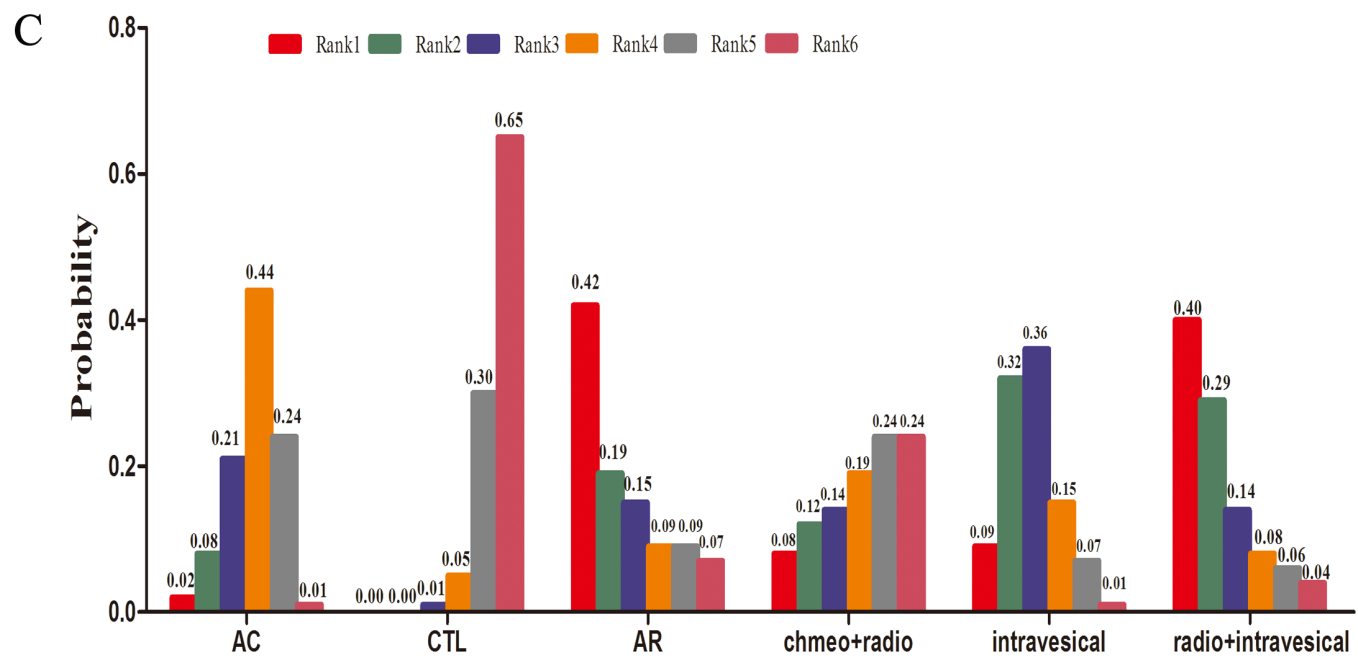

Figure 4: Values of the different rankings of the treatment strategies. A OS, B DSS and C RFS 
demonstrates a considerable beneficial effect on DSS (HR 0.25, 95\% CI 0.06-0.61). The HRs were 0.36 for the indirect comparison of NAC with AC and 6.89 for the comparison between AR and NAC, suggesting that NAC holds an obvious advantage on improving patient DSS. Survival benefit is also observed in terms of OS (HR 0.46, 95\% CI 0.13-1.07) in our study. NAC exhibited some drawbacks, including overtreatment of non-responders and impairment of renal and hepatic function. Nevertheless, patients could still benefit from NAC. For instance, NAC may cure micrometastatic disease, reduce the circle tumour cells and prolong survival. Several studies reported that NAC could prolong the survival of patients with bladder cancer [29], improve the complete response rate and downstaging rate in UTUC patients [27]. These findings support the use of NAC in UTUC patients. The contemporary view is that NAC should be better than AC. Large prospective RCTs are needed to determine whether this is true in UTUC.

For most common cancers, AR is essential to control local-regional recurrence, palliate symptoms and manage localised disease [30]. In UTUC patients, the rate of localregional recurrence may reach up to $45 \%$ [31]. Thus, the role of AR must be addressed. Controversial results on the effectiveness of AR were reported in previous studies $[11,12,32]$. In our study, AR demonstrates no beneficial effect for the improvement of OS (HR 0.83, 95\% CI 0.39-1.47), DSS (HR 1.02, 95\% CI 0.46-1.86) and RFS (HR 0.39 , 95\% CI 0.02-1.33). This finding may be due to the fact that the patients included in previous studies involved different clinical stages and pathological grades that we cannot adjust. Furthermore, the relatively small number of patients in our study also limits our accuracy in assessing the role of AR. Our data indicate that concurrent chemoradiotherapy shows no survival benefit in terms of OS and RFS, which contradicts the findings from previous studies $[12,26]$. By contrast, utilisation of AC alone can improve both OS and RFS, as shown in Figure 3. This result may be attributed to the side effects of radiotherapy. Furthermore, UTUC patients are usually elderly [24] who are underrepresented in oncology trials [33], suggesting that they were at higher risk of side effect of radiotherapy. Our results are consistent with the 2015 EAU guideline that radiotherapy is no longer relevant, either alone or as adjunct to chemotherapy [24].

Two independent prospective randomised controlled trials demonstrated that postoperative instillation of intravesical mitomycin $\mathrm{C}$ with or without cytosine arabinoside reduces the risk of recurrence of bladder tumours after surgery for UTUCs $[14,34]$. This treatment was confirmed in other prospective randomised trials to be replaced by pirarubicin $[13,35]$ and in a metaanalysis [34]. In our study, intravesical chemotherapy (HR 0.32, 95\% CI 0.09-0.69) is noted to prolong RFS by $68 \%$. Interestingly, the HR of concurrent radiotherapy and intravesical chemotherapy is 0.32 , and concurrent radiotherapy plus intravesical chemotherapy is not better than intravesical chemotherapy alone (HR 1.02, 95\% CI 0.15-2.90). This finding may be attributed to the conclusion discussed above that radiotherapy is no longer relevant, either alone or as an adjunct to chemotherapy [24]. Our work demonstrates that patients should receive prophylactic intravesical chemotherapy after nephroureterectomy to reduce recurrence.

Several limitations exist in our study. First, we analysed data from previous trials rather than individual patient data. Similar covariates, which might affect the final outcomes, are present at the individual patient level, which we cannot adjust. Secondly, for the analysis of NAC versus AC, only one study was included due to the limited number of published studies which might weaken the conclusion.Another limitation is that RNU was performed by various surgeons across different trials over a long period, which might influence survival to a large extent. Additionally, significant heterogeneity exists among the procedures adopted in the studies. For example, different trials exploring $\mathrm{AC}$ varies in the regimen, dosage and number of cycles. Nevertheless, our study also offered several advantages as follows. When direct comparisons were unavailable, our network meta-analysis assessed the efficacy of different treatment strategies. This metaanalysis can combine direct and indirect comparisons to strengthen the efficiency and reliability of the study. The measures of survival also varied among studies. Our meta-analysis overcame this disadvantage through a single analysis using the HR scale, thereby avoiding potential selection bias and loss of information from only including studies with the same measure or performing separate analyses for different measures [36]. Our work synthesised all available existing evidence and provided new evidence on controversial issues, presenting important implications in clinical practice and future research.

In conclusion, our results suggest that both $\mathrm{AC}$ and NAC improve OS and DFS of UTUC patients after RNU. Furthermore, AR is found to no longer be relevant for use either alone or as an adjunct to chemotherapy. Finally, AC, intravesical chemotherapy or concurrent radiotherapy and intravesical chemotherapy prolong RFS.

\section{ACKNOWLEDGMENTS}

We thanked the statistical contribution from Yuanchen Lu (a8911@qq.com). This work was supported by the National Natural Science Foundation of China (grants No. 81272832 and 81201997), the Priority Academic Program Development of Jiangsu Higher Education Institutions (PAPD) and Jiangsu Provincial Special Program of Medical Science (BL2012027). The funders had no role in study design, data collection and analysis, decision to publish, or preparation of the manuscript. 


\section{CONFLICTS OF INTEREST}

Authors have nothing to disclose.

\section{REFERENCES}

1. Siegel R, Naishadham D and Jemal A. Cancer statistics, 2012. CA: a cancer journal for clinicians. 2012; 62(1):1029.

2. Smith P, Mandel J and Raman JD. Conservative nephronsparing treatment of upper-tract tumors. Current urology reports. $2013 ; 14(2): 102-108$.

3. Lucca I, Leow JJ, Shariat SF and Chang SL. Diagnosis and Management of Upper Tract Urothelial Carcinoma. Hematology/oncology clinics of North America. 2015; 29(2):271-288.

4. Margulis V, Shariat SF, Matin SF, Kamat AM, Zigeuner R, Kikuchi E, Lotan Y, Weizer A, Raman JD and Wood CG. Outcomes of radical nephroureterectomy: a series from the Upper Tract Urothelial Carcinoma Collaboration. Cancer. 2009; 115(6):1224-1233.

5. Kang M, Jeong CW, Kwak C, Kim HH and $\mathrm{Ku}$ JH. The characteristics of recurrent upper tract urothelial carcinoma after radical nephroureterectomy without bladder cuff excision. Yonsei medical journal. 2015; 56(2):375-381.

6. Leow JJ, Martin-Doyle W, Rajagopal PS, Patel CG, Anderson EM, Rothman AT, Cote RJ, Urun Y, Chang SL, Choueiri TK and Bellmunt J. Adjuvant Chemotherapy for Invasive Bladder Cancer: A 2013 Updated Systematic Review and Meta-Analysis of Randomized Trials. European urology. 2014; 66(1):42-54

7. Porten S, Siefker-Radtke AO, Xiao L, Margulis V, Kamat AM, Wood CG, Jonasch E, Dinney CP and Matin SF. Neoadjuvant chemotherapy improves survival of patients with upper tract urothelial carcinoma. Cancer. 2014; 120(12):1794-1799.

8. Cai G, Liu X and Wu B. Treatment of upper urinary tract urothelial carcinoma. Surgical oncology. 2011; 20(1):43-55.

9. Maulard-Durdux C, Mejean A, Dufour B, Hennequin C, Chretien Y, Vignes B, Droz D, Delanian S and Housset M. Value of postoperative radiotherapy in malignant tumors of the upper urinary tract. Apropos of a series of 26 patients. Bulletin du cancer. 1996; 83(11):940-944.

10. Jwa E, Kim YS, Ahn H, Kim CS, Lee JL, Kim SO and S DOA. Adjuvant radiotherapy for stage III/IV urothelial carcinoma of the upper tract. Anticancer research. 2014; 34(1):333-338.

11. Chen B, Zeng ZC, Wang GM, Zhang L, Lin ZM, Sun LA, Zhu TY, Wu LL, Zhang JY and Ji Y. Radiotherapy may improve overall survival of patients with T3/T4 transitional cell carcinoma of the renal pelvis or ureter and delay bladder tumour relapse. BMC cancer. 2011; 11:297.

12. Czito B, Zietman A, Kaufman D, Skowronski U and Shipley W. Adjuvant Radiotherapy with and without Concurrent
Chemotherapy for Locally Advanced Transitional Cell Carcinoma of the Renal Pelvis and Ureter. The Journal of urology. 2004; 172(4):1271-1275.

13. Wu WJ, Ke HL, Yang YH, Li CC, Chou YH and Huang $\mathrm{CH}$. Should patients with primary upper urinary tract cancer receive prophylactic intravesical chemotherapy after nephroureterectomy? The Journal of urology. 2010; 183(1):56-61.

14. O'Brien T, Ray E, Singh R, Coker B, Beard R and British Association of Urological Surgeons Section of O. Prevention of bladder tumours after nephroureterectomy for primary upper urinary tract urothelial carcinoma: a prospective, multicentre, randomised clinical trial of a single postoperative intravesical dose of mitomycin $\mathrm{C}$ (the ODMIT-C Trial). European urology. 2011; 60(4):703-710.

15. Ito A, Shintaku I, Satoh M, Ioritani N, Tochigi T, Numata I, Namima T, Kambe K, Kyan A, Ueno S, Katoh S, Adachi $\mathrm{H}$, Yamashita $\mathrm{S}$, et al. Intravesical seeding of upper urinary tract urothelial carcinoma cells during nephroureterectomy: an exploratory analysis from the THPMG trial. Japanese journal of clinical oncology. 2013; 43(11):1139-1144.

16. Deng $\mathrm{X}$, Yang $\mathrm{X}$, Cheng $\mathrm{Y}$, Liu X, Wu B, Wang Z, Huang Z, Liu K, Zhao R, Wang J, Lu Q, Qin C and Yin C. Prognostic value and efficacy valuation of postoperative intravesical instillation in primary urothelial carcinomas of upper urinary tract. International journal of clinical and experimental medicine. 2014; 7(12):4734-4746.

17. Tierney JF, Stewart LA, Ghersi D, Burdett S and Sydes MR. Practical methods for incorporating summary time-toevent data into meta-analysis. Trials. 2007; 8:16.

18. Brooks SP and Gelman A. General Methods for Monitoring Convergence of Iterative Simulations. Journal of Computational and Graphical Statistics. 1998; 7(4):434455 .

19. Wells GA SB, O'Connell D, Peterson'Connell J, Welch V, et al. The Newcastle-Ottawa Scale (NOS) for assessing the quality of nonrandomised studies in meta-analyses. 2013.

20. Yafi FA, Tanguay S, Rendon R, Jacobsen N, Fairey A, Izawa J, Kapoor A, Black P, Lacombe L, Chin J, So A, Lattouf JB, Bell D, et al. Adjuvant chemotherapy for uppertract urothelial carcinoma treated with nephroureterectomy: assessment of adequate renal function and influence on outcome. Urologic oncology. 2014; 32(1):31 e17-24.

21. Lee KS, Kim KH, Yoon YE, Choi KH, Yang SC and Han WK. Impact of adjuvant chemotherapy in patients with upper tract urothelial carcinoma and lymphovascular invasion after radical nephroureterectomy. Korean journal of urology. 2015; 56(1):41-47.

22. Huang YC, Chen MF, Shi CS, Shindel AW, Huang CE, Pang ST, Chuang CK, Chen CS, Chang YH, Lin WY, Ho DR, Chin CC, Kuo YH and Wu CF. The Efficacy of Postoperative Adjuvant Chemotherapy for Patients with pT3N0M0 Upper Tract Urothelial Carcinoma. The Journal of urology. 2015; 194(2):323-330. 
23. Sengelov L, Kamby C, Schou G and von der Maase H. Prognostic factors and significance of chemotherapy in patients with recurrent or metastatic transitional cell cancer of the urinary tract. Cancer. 1994; 74(1):123-133.

24. Roupret M, Babjuk M, Comperat E, Zigeuner R, Sylvester RJ, Burger M, Cowan NC, Bohle A, Van Rhijn BW, Kaasinen E, Palou J and Shariat SF. European Association of Urology Guidelines on Upper Urinary Tract Urothelial Cell Carcinoma: 2015 Update. European urology. 2015.

25. Witjes JA, Comperat E, Cowan NC, De Santis M, Gakis G, Lebret T, Ribal MJ, Van der Heijden AG, Sherif A and European Association of U. EAU guidelines on muscleinvasive and metastatic bladder cancer: summary of the 2013 guidelines. European urology. 2014; 65(4):778-792.

26. Vassilakopoulou M, de la Motte Rouge T, Colin P, Ouzzane A, Khayat D, Dimopoulos MA, Papadimitriou CA, Bamias A, Pignot G, Nouhaud FX, Hurel S, Guy L, Bigot $\mathrm{P}$, Roumiguie M, Roupret $\mathrm{M}$ and French Collaborative National Database on U-U. Outcomes after adjuvant chemotherapy in the treatment of high-risk urothelial carcinoma of the upper urinary tract (UUT-UC): results from a large multicenter collaborative study. Cancer. 2011; 117(24):5500-5508.

27. Matin SF, Margulis V, Kamat A, Wood CG, Grossman HB, Brown GA, Dinney CP, Millikan R and Siefker-Radtke AO. Incidence of downstaging and complete remission after neoadjuvant chemotherapy for high-risk upper tract transitional cell carcinoma. Cancer. 2010; 116(13):31273134.

28. Leow JJ, Martin-Doyle W, Fay AP, Choueiri TK, Chang SL and Bellmunt J. A systematic review and meta-analysis of adjuvant and neoadjuvant chemotherapy for upper tract urothelial carcinoma. European urology. 2014; 66(3):529541.

29. Rosenblatt R, Sherif A, Rintala E, Wahlqvist R, Ullen A, Nilsson S, Malmstrom PU and Nordic Urothelial Cancer G. Pathologic downstaging is a surrogate marker for efficacy and increased survival following neoadjuvant chemotherapy and radical cystectomy for muscle-invasive urothelial bladder cancer. European urology. 2012; 61(6):1229-1238.

30. Barton MB, Jacob S, Shafiq J, Wong K, Thompson SR, Hanna TP and Delaney GP. Estimating the demand for radiotherapy from the evidence: a review of changes from 2003 to 2012. Radiotherapy and oncology. 2014; 112(1):140-144.

31. Ozsahin M, Zouhair A, Villa S, Storme G, Chauvet B, Taussky D, Gouders D, Ries G, Bontemps P, Coucke PA and Mirimanoff RO. Prognostic factors in urothelial renal pelvis and ureter tumours: a multicentre Rare Cancer Network study. European journal of cancer (Oxford, England : 1990). 1999; 35(5):738-743.

32. Hall MC, Womack JS, Roehrborn CG, Carmody T and Sagalowsky AI. Advanced transitional cell carcinoma of the upper urinary tract: patterns of failure, survival and impact of postoperative adjuvant radiotherapy. The Journal of urology. 1998; 160(3 Pt 1):703-706.

33. Hutchins LF, Unger JM, Crowley JJ, Coltman CA, Jr. and Albain KS. Underrepresentation of patients 65 years of age or older in cancer-treatment trials. The New England journal of medicine. 1999; 341(27):2061-2067.

34. Fang D, Li XS, Xiong GY, Yao L, He ZS and Zhou LQ. Prophylactic intravesical chemotherapy to prevent bladder tumors after nephroureterectomy for primary upper urinary tract urothelial carcinomas: a systematic review and metaanalysis. Urologia internationalis. 2013; 91(3):291-296.

35. Ito A, Shintaku I, Satoh M, Ioritani N, Aizawa M, Tochigi T, Kawamura S, Aoki H, Numata I, Takeda A, Namiki $\mathrm{S}$, Namima $\mathrm{T}$, Ikeda $\mathrm{Y}$, et al. Prospective randomized phase II trial of a single early intravesical instillation of pirarubicin (THP) in the prevention of bladder recurrence after nephroureterectomy for upper urinary tract urothelial carcinoma: the THP Monotherapy Study Group Trial. Journal of clinical oncology. 2013; 31(11):1422-1427.

36. Liao W-C, Chien K-L, Lin Y-L, Wu M-S, Lin J-T, Wang H-P and Tu Y-K. Adjuvant treatments for resected pancreatic adenocarcinoma: a systematic review and network meta-analysis. The Lancet Oncology. 2013; 14(11):1095-1103.

37. Lee SE, Byun SS, Park YH, Chang IH, Kim YJ and Hong SK. Adjuvant chemotherapy in the management of pT3N0M0 transitional cell carcinoma of the upper urinary tract. Urologia internationalis. 2006; 77(1):22-26.

38. Seitz C, Gupta A, Shariat SF, Matsumoto K, Kassouf W, Walton TJ, Fritsche HM, Otto W, Tritschler S, Bastian PJ, Carballido J, Ficarra V, Karakiewicz PI, et al. Association of tumor necrosis with pathological features and clinical outcome in 754 patients undergoing radical nephroureterectomy for upper tract urothelial carcinoma: an international validation study. The Journal of urology. 2010; 184(5):1895-1900.

39. Kawashima A, Nakai Y, Nakayama M, Ujike T, Tanigawa G, Ono Y, Kamoto A, Takada T, Yamaguchi Y, Takayama $\mathrm{H}$, Nishimura K, Nonomura $\mathrm{N}$ and Tsujimura A. The result of adjuvant chemotherapy for localized pT3 upper urinary tract carcinoma in a multi-institutional study. World journal of urology. 2012; 30(5):701-706.

40. Kluth LA, Xylinas E, Kent M, Hagiwara M, Kikuchi E, Ikeda M, Matsumoto K, Dalpiaz O, Zigeuner R, Aziz A, Fritsche HM, Deliere A, Raman JD, et al. Predictors of survival in patients with disease recurrence after radical nephroureterectomy. BJU international. 2014; 113(6):911917.

41. Raman JD, Lin YK, Kaag M, Atkinson T, Crispen P, Wille M, Smith N, Hockenberry M, Guzzo T, Peyronnet B, Bensalah K, Simhan J, Kutikov A, et al. High rates of advanced disease, complications, and decline of renal function after radical nephroureterectomy. Urologic oncology. 2014; 32(1):47 e49-14.

42. Kim TS, Oh JH and Rhew HY. The efficacy of adjuvant 
chemotherapy for locally advanced upper tract urothelial cell carcinoma. Journal of Cancer. 2013; 4(8):686-690.

43. Kuriyama M, Takeuchi T, Fujihiro S, Fujimoto Y, Shinoda I, Takahashi Y, Yamada S and Nishiura T. Adjuvant chemotherapy for uroepithelial transitional cell carcinoma. Cancer chemotherapy and pharmacology. 1987; 20 Suppl:S29-33.

44. Cozad SC, Smalley SR, Austenfeld M, Noble M, Jennings $\mathrm{S}$ and Reymond R. Adjuvant radiotherapy in high stage transitional cell carcinoma of the renal pelvis and ureter. International journal of radiation oncology, biology, physics. 1992; 24(4):743-745.

45. Suzuki S, Shinohara N, Harabayashi T, Sato S, Abe T and Koyanagi T. Impact of adjuvant systemic chemotherapy on postoperative survival in patients with high-risk urothelial cancer. International journal of urology. 2004; 11(7):456460.

46. Kwak C, Lee SE, Jeong IG and Ku JH. Adjuvant systemic chemotherapy in the treatment of patients with invasive transitional cell carcinoma of the upper urinary tract. Urology. 2006; 68(1):53-57.

47. Soga N, Arima K and Sugimura Y. Adjuvant methotrexate, vinblastine, adriamycin, and cisplatin chemotherapy has potential to prevent recurrence of bladder tumors after surgical removal of upper urinary tract transitional cell carcinoma. International journal of urology. 2008; 15(9):800-803.

48. Hellenthal NJ, Shariat SF, Margulis V, Karakiewicz PI, Roscigno M, Bolenz C, Remzi M, Weizer A, Zigeuner R, Bensalah K, Ng CK, Raman JD, Kikuchi E, et al. Adjuvant chemotherapy for high risk upper tract urothelial carcinoma: results from the Upper Tract Urothelial Carcinoma Collaboration. The Journal of urology. 2009; 182(3):900906.
49. Fan KH, Chen YC, Leung WM, Chuang CK, Pang ST and Hong JH. Adjuvant and salvage radiotherapy for urothelial cell carcinoma of the upper urinary tract: experience in a single institution. Chang Gung medical journal. 2012; $35(3): 247-254$.

50. Kitamura H, Igarashi M, Tanaka T, Shindo T, Masumori N, Tamakawa M, Kawaai Y and Tsukamoto T. A role for preoperative systemic chemotherapy in node-positive upper tract urothelial carcinoma treated with radical nephroureterectomy. Japanese journal of clinical oncology. 2012; 42(12):1192-1196.

51. Cozad SC, Smalley SR, Austenfeld M, Noble M, Jennings $\mathrm{S}$ and Raymond R. Transitional cell carcinoma of the renal pelvis or ureter: patterns of failure. Urology. 1995; 46(6):796-800.

52. Sakamoto N, Naito S, Kumazawa J, Ariyoshi A, Osada Y, Omoto T, Fujisawa Y, Morita I and Yamashita H. Prophylactic intravesical instillation of mitomycin $\mathrm{C}$ and cytosine arabinoside for prevention of recurrent bladder tumors following surgery for upper urinary tract tumors: a prospective randomized study. International journal of urology. 2001; 8(5):212-216.

53. Shirotake S, Kikuchi E, Tanaka N, Matsumoto K, Miyazaki Y, Kobayashi H, Ide H, Obata J, Hoshino K, Kaneko G, Hagiwara M, Kosaka T, Kanao K, et al. Impact of an adjuvant chemotherapeutic regimen on the clinical outcome in high risk patients with upper tract urothelial carcinoma: a Japanese multi-institution experience. The Journal of urology. 2015; 193(4):1122-1128. 